\title{
Meteorological Hazards - Visualization System for National Protection Against Extreme Hazards for Poland
}

\author{
Agnieszka Wypych, Zbigniew Ustrnul \\ Institute of Meteorology and Water Management, National Research Institute, Kraków Branch, Piotra Borowego Street 14, \\ 30-215 Kraków,Poland, e-mail: agnieszka.wypych@imgw.pl, zbigniew.ustrnul@imgw.pl \\ Jagiellonian University, Department of Climatology, Gronostajowa Street 7, 30-387 Kraków, Poland
}

\author{
Ewelina Henek \\ Institute of Meteorology and Water Management, National Research Institute, Kraków Branch, Piotra Borowego Street 14, \\ 30-215 Kraków, Poland, e-mail: ewelina.henek@imgw.pl
}

\begin{abstract}
Meteorological hazard maps are one of the components of the IT System for Country Protection against extreme hazards (ISOK) created by a consortium of Polish institutions, including the Institute of Meteorology and Water Management - National Research Institute. These maps present meteorological phenomena such as: temperature extremes, heavy and flood-producing rainfall, strong winds, intensive snowfall, fogs, glaze, rime and thunderstorms with hail. These elements were chosen arbitrarily due to recorded or estimated losses. The main aim of the maps is to present visualization methods of hazard forecast with consideration of climatological (historical) background. To identify areas especially exposed to the above meteorological hazards, extensive climatological analyses were performed, based on long-term daily data (mainly the 1951-2010 period). The main component of the warning system is a set of prediction maps created automatically on the basis of scientific algorithms that provide the probability of the occurrence of particular phenomena, or the conditions favourable for them. The algorithms' structure, based on information about physical processes in the atmosphere, as well as detailed climatological analysis, enables the reclassification of the forecast values - predicted by the ALADIN mesoscale atmospheric model - into four groups of any hazard at the gridded points. Finally, the information will be interpolated and will result in the production of maps of spatial distribution presenting the objective probability of a particular hazard, i.e. its actual risk. Results of historical analysis are to be presented for the public by a number of climatological maps, and accompanied by additional fact sheets to provide society with an actual view of the spatial distribution of the distinguished weather phenomena, and the interrelated risks.
\end{abstract}

Key words: meteorological hazards, warning system, climatic maps, Poland

Submitted 20 March 2014, revised 1 July 2014, accepted 1 July 2014

\section{Introduction}

The information on current and forecast weather conditions is, by and large, indispensable for everyday life, especially in cases of extreme phenomena. When such conditions become dangerous, they may cause huge material losses, and even put people's health and lives at risk.

Present technological development, which includes remote sensing and geographic information systems, along with the knowledge of atmospheric processes and other determinants of weather variability, can effectively support operational weather forecasting and, consequently, the protection of people's lives and property.

One of the fundamental concerns of meteorological activity is to provide society with the tools for reducing the impact of weather-, climate- and water-related hazards (WMO 2012). Within the framework of the Disaster Risk Reduction Programme, national meteorological and hydrological services should develop methods of observing, detecting, monitoring and predicting various hazards, as well as methods of issuing early warnings of various hazards (Golnaraghi 2012; Tiukało 2013). Primarily, the importance of historical information is stressed as necessary for the identification of hazard impact or further risk - this is done through the recognition of hazard patterns. Calculating probabilities of their occurrence or severity (WMO 2008) confirms that strong winds, heavy snow, river floods and heat waves are listed at the top hydrometeorological hazards affecting Europe; events of thunderstorms and hailstorms, freezing rain and dense fogs are only slightly less dangerous.

The objective of this study is to present the distribution of chosen extreme weather phenomena in various parts of Poland from climatological and forecasting aspects. It is also, particularly, an attempt to define a method of initiating a permanent warning system (based on automated operations) to protect society against extreme weather events. When the system becomes fully operational, weather ha-zard maps will show current information (updated every 12 hours) on potentially endangered regions, 
accompanied by a visualization of the conditions favourable for particular hazards - predicted within 48-hour timespan. The maps will also facilitate the identification (based on historical analysis) of the areas in which potential hazards may occur.

\section{Data and methods}

\subsection{Elaborated data}

Based on available values and length of continuous observations, the following elements were selected for further analyses as selection criteria: temperature extremes, heavy and flood-producing rainfall, strong wind, intensive snowfall, fogs, glaze, rime and thunderstorms with hail. For each extremity, three components were produced: climatological maps, warning maps and supplementary material.

The climatological maps were created in accordance with the WMO guidelines (Klein Tank et al. 2009), on the basis of the longest and most homogenous weather data series available: from 1951-2010 for air temperature and precipitation - and from 1966-2010 for other elements. The data was obtained from synoptic and climatic weather stations. In some cases it was also derived from precipitation stations. Some general statistics and characteristics of probability were calculated for the analyzed elements. This was followed by detailed identification of which analyzed elements were hazardous.

\subsection{Definition of observed hazards}

Extreme cases were defined for temperature, heavy rainfall and snowfall (the only chosen characteristics). The issue of extremes and their criteria is currently a subject of worldwide discussion (e.g. Brönnimann et al. 2008; Stephenson 2008) and, having considered different proposed approaches to determining extremes in historical analysis, probabilities of 25\% (snowfall only), 10\%, 5\% (snowfall excluded), and $1 \%$ of occurrence was eventually used. In a practical sense this means that a given extreme can occur once per 4, 10, 20, and 100 cases respectively. Due to the dense weather station network (with data collected from the five types of the IMGW-PIB measurement and observation stations available) and the vast temporal variability of the abovementioned elements, the maps were created with a decadal resolution - 36 maps showing the characteristics of each element. As no entirely universal method of interpolation has yet been found (based on studies conducted by international research teams - Dobesch et al. 2007), the maps were created using the methods most frequently used in climatology: ordinary kriging, residual kriging, and in some cases other methods, referred to as 'combined'. In addition to the maps mentioned, the continuous contour maps showing the once in 2-year, 5-year, and 10-year probabilities of occurrence were created for maximum wind gusts. In this case, however, because of the sparse station network and a significant replacement of equipment in the stations, data from the WRF-ARW 3.2.1 mesoscale numerical model was used (Soares et al. 2012; Brasseur 2001).

Other characteristics of wind speed, as well as snowfall and snow-cover, along with maps showing the risk of fog, glaze, hailstorm, and rime, are depicted in the form of signature, with monthly and seasonal resolution. For strong wind and snowfall, the highest values of determined probability of occurrence, and also the highest measured values in the analyzed period, are shown. In the case of the thunderstorms with hail, fog, rime, and glaze, both a phenomenon's frequency of occurrence at selected stations in the territory of Poland, and the probability of conditions favourable for their occurrence are presented. Maps of conditions favourable for the occurrence of phenomena were constructed relying on knowledge of the physical atmospheric processes responsible, i.e. air temperature and humidity conditions, precipitation, wind speed, vertical atmosphere stratification. As a reference, data from aerological soundings, aviation weather reports, as well as standard data was used; spatial differentiation was achieved with the use of data from The Regional Climate Model RegCM (Elguindi et. al 2011). For a fog phenomenon, weather conditions were also related to environmental ones favourable for its occurrence, i.e. topography and land cover, thanks to which spatial differentiation also shows mesoscale phenomena likely to develop or be intensified due to favourable local conditions.

\subsection{Maps in the operational system}

Warning maps will be generated in the ISOK system (in automatic mode), relying on formulated algorithms describing the occurrence of meteorological hazards. The algorithms will facilitate the generation of maps forecasting the probability of the occurrence of defined hazards (temperature extremes, heavy rainfall, strong winds, snowfall) or the occurrence of conditions supporting the appearance of a given phenomenon (thunderstorms with hail, fog, rime, glaze). Hazard classes will be defined based on the results of the ALADIN weather prediction model for the nearest 12, 24, and 48 hours.

The algorithms' structure allows us to reclassify predicted values (using the ALADIN mesoscale atmospheric model) on the grid points (with a spatial resolution of $7.4 \mathrm{~km}$ ) into four groups of hazards - here they are limited by the previously set values of the parameters used in the algorithm (heavy wind, snowfall, hailstorm, fog, rime, glaze), or by values which are generated on the basis of historical analysis (temperature extremes, heavy rainfall).

The algorithm maps, being also the basis for the warning, apply three scenarios: in the first, prediction data from the ALADIN mesoscale meteorological model is reclassified into arbitrarily selected intervals; the second scenario, (Fig. 1) assumes that the threshold values generated from the historical analysis (with a defined probability of occurrence in a given area) are the basis for the delimita- 


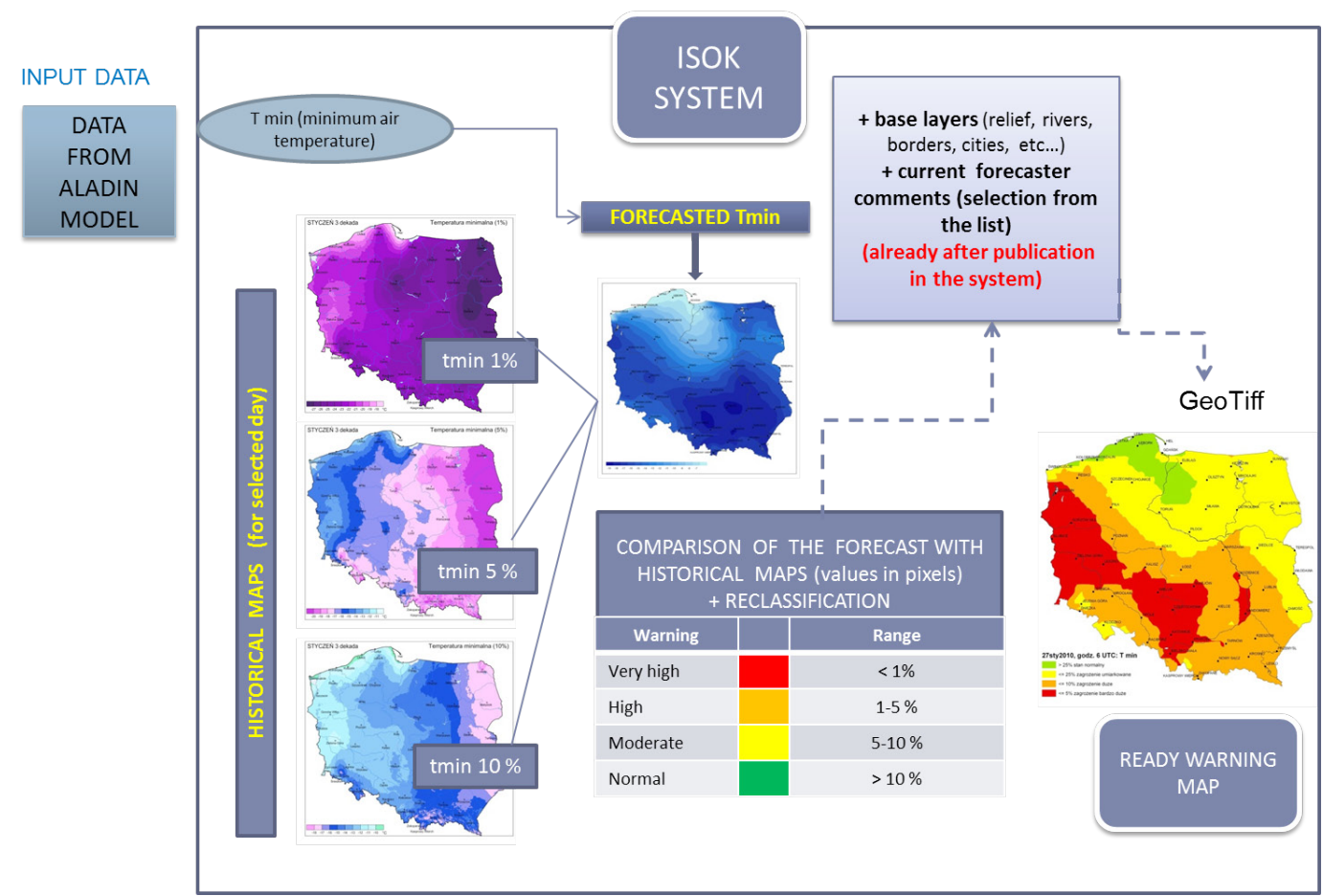

Fig. 1. The workflow of the automatic generation of warning maps- climatological approach

Explanations: Values of particular percentiles (defined to be extreme based on climatological analysis) are used as the thresholds for distinguishing hazard classes. Forecast values from the ALADIN model are reclassified within the four classes and interpolated to produce the final warning map

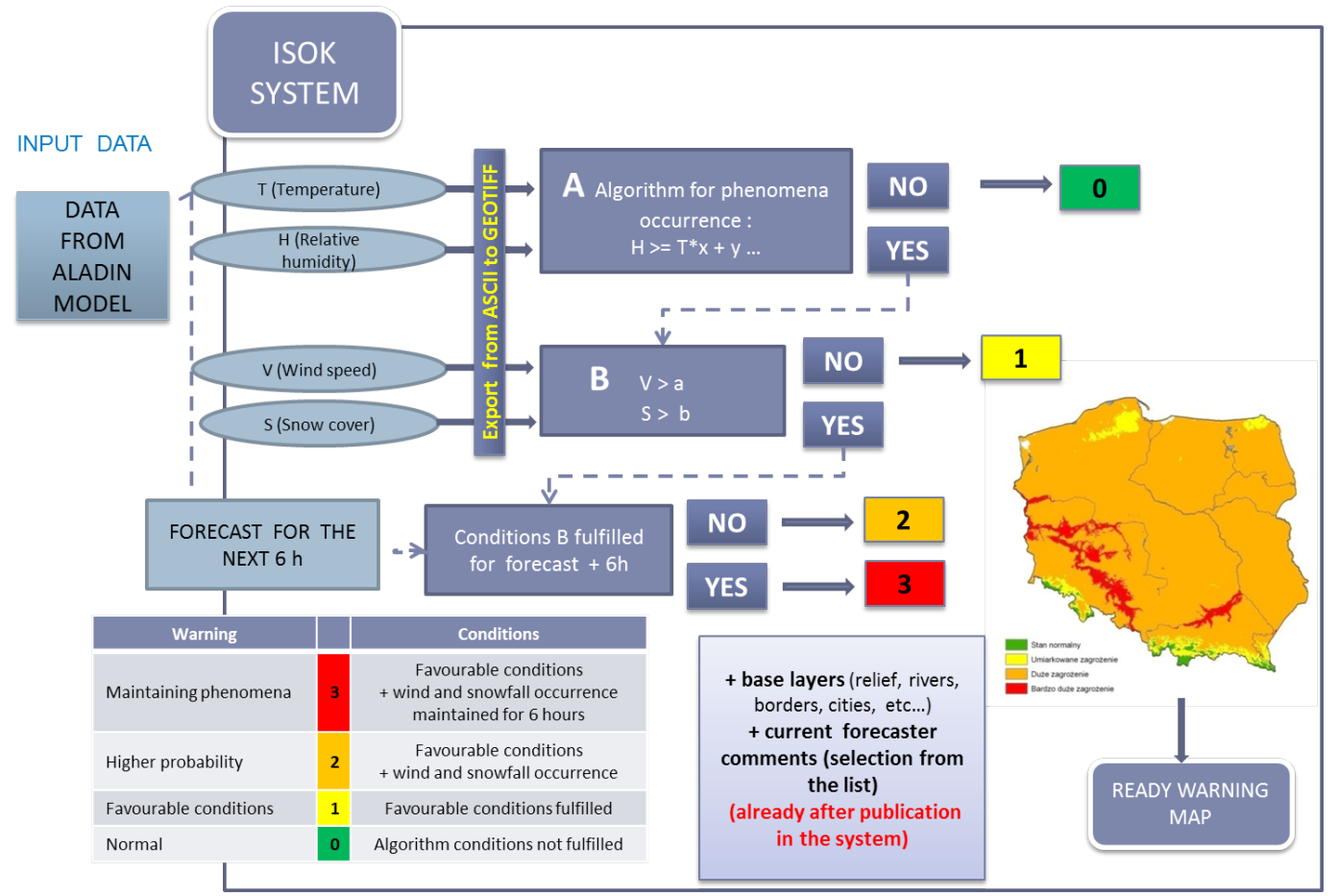

Fig. 2. The workflow of the automatic generation of warning maps - algorithm approach

Explanations: Values of weather elements specified as favourable for the occurrence of a phenomenon are processed according to the defined algorithms. If the particular condition is fulfilled, forecast values from the ALADIN model are reclassified within the four classes and interpolated to produce the final warning map

tion of the risk classes; in the third scenario (Fig. 2), the data from the ALADIN model is calculated according to an algorithm (which includes mathematical and logical expressions) explaining weather conditions that favour the occurrence of a phenomenon. After this, the data is reclassified into four arbitrarily selected groups. 
As supplementary material, descriptions of hazards related to the occurrences of extreme meteorological events, complemented with additional graphic material (diagrams, tables), will be included, specifically: a definition and description of a given phenomenon and the conditions supporting its occurrence; identification and definition of a hazard related to the occurrence of a given phenomenon, as well as its seasonal differentiation; and case studies of the extremes recorded so far. The material will assist the analysis and interpretation of meteorological hazard maps.

\subsection{Validation formulae for the operational maps}

The entirely automatically generated maps will be ve-rified by a weather forecaster, who will confirm their correctness or provide short comments when the atmospheric conditions change rapidly or the information provided by the ALADIN model is not complete.

Every algorithm underwent a thorough validation through different estimation parameters using featurebased statistics.

In order to describe the forecasting accuracy, probability of detection $(P O D)$ characteristics (1) were calculated. As the indicator is very sensitive to the climatological frequency of an event, it appears to be a good measure with respect to the analyzed phenomena (Casati et al. 2008): where:

$$
P O D=\frac{E_{0 \cap f}}{E_{0}}
$$

$P O D$ - probability of detection,

$E_{o \cap f}$ - number of phenomena observed and forecast ('hits'), $E_{o}$ - total number of observed phenomena.

Conditional probability $(P O D)$ is a good statistic for describing the 'hits', though it ignores false alarms. Therefore a false alarm ratio statistic (FAR) was also introduced (2), as is recommended when working with POD (Stanski et al. 1989).

$$
F A R=\frac{E_{f \neq 0}}{E_{f}}
$$

where:

$F A R$ - false alarm ratio,

$E_{f \neq o}-$ number of phenomena forecast but not observed ('false alarms'),

$E_{f}$ - total number of forecast phenomena.

The algorithms will eventually be employed in the system as the basis of the prediction of phenomena, therefore their validation was accomplished simultaneously on two sets of information (the historical and the operational, the latter derived from the ALADIN model). The results of the validation clearly indicate satisfactory outcomes, reaching $90 \%$ probability of detection $(P O D)$ for every analyzed element. At the same time, false alarm ratio values were also definitely high. While it is true that the results vary seasonally, the oscillation within the $20-60 \%$ frame suggests that further tests and analyses are required for the improvement of the quality of the prediction of favourable conditions.

It should be remembered that local conditions (e.g. topography, water bodies, land-cover) often intensify the courses of phenomena. However, it is not possible to include this local situation on the maps, which are constructed with the use of algorithms, and the aim of which is to predict favourable weather conditions. Additionally, the results are often greatly affected by the quality of the actual meso-meteorological predictions (including the spatial resolution of the weather). This issue, however, exceeds the bounds of this study.

\section{Results}

As stated in the introduction, the aim of meteorological hazard maps is to present the spatial distribution of extreme weather phenomena that occurred in the specified long-term period (using climatological maps), and to indicate the regions for which the phenomena are predicted.

The so-called historical maps are a climatological expression of the analyzed hazards. By representing the spatial differentiation of the elements' and phenomena's extreme values, estimated with the probability of their occurrences in Poland (e.g. Fig. 3 - extreme temperatures, Fig. 4 - extreme snow cover growth), they serve as background information for the warning maps. In numerous cases, they also represent the frequency of the values above the threshold in a given season (e.g. Fig. 5 - extreme precipitation, Fig. 6 - extreme wind speed). The climatological maps are a selection of characteristics and indices which were found to be crucial for the representation of particular hazards - when their temporal and spatial variability is considered. A monthly approach is the most fundamental one, yet, owing to great the variability in an annual course, some of them are represented in a decadal scale.

As mentioned in the methodology section, due to the lack of relevant data, detailed analyses of the coexistence of specific weather conditions and atmospheric processes contributing to the occurrence of weather phenomena, such as hailstorms, fog, rime and glaze, were conducted. As a result, the maps of the atmospheric conditions favourable to their development were created (Fig. 7 - glazefavourable conditions).

Warning maps will provide information on the probability of occurrences of extremes, which in certain cases may directly threaten the environment and its inhabitants or have a great impact on everyday human life. The maps will be generated automatically in the system and serve as a graphic representation of the chosen weather hazard 

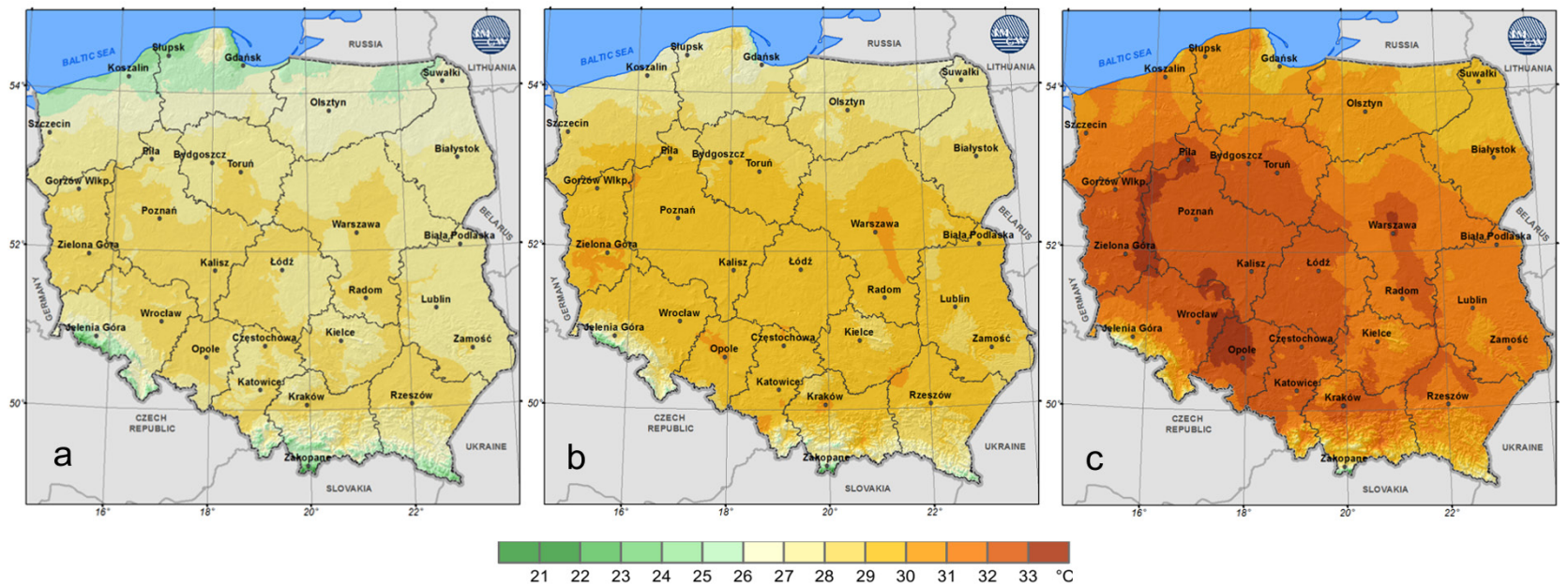

Fig. 3. Spatial distribution of maximum air temperature $\left({ }^{\circ} \mathrm{C}\right.$ ) with the occurrence probability of $10 \%$ (a), $5 \%$ (b) and $1 \%$ (c) - June, 3rd decade

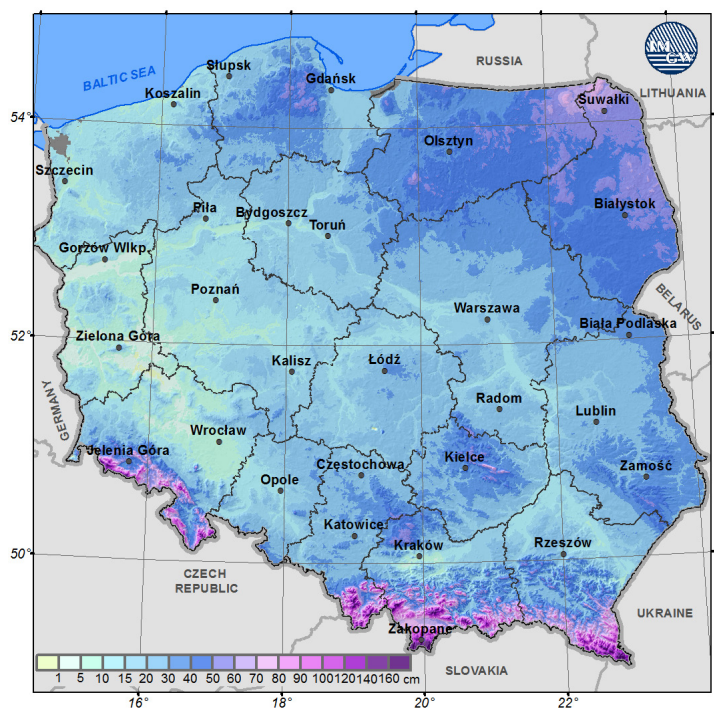

Fig. 4. Spatial distribution of snow-cover depth $(\mathrm{cm})$ with the occurrence probability of $1 \%$ - March, 3rd decade

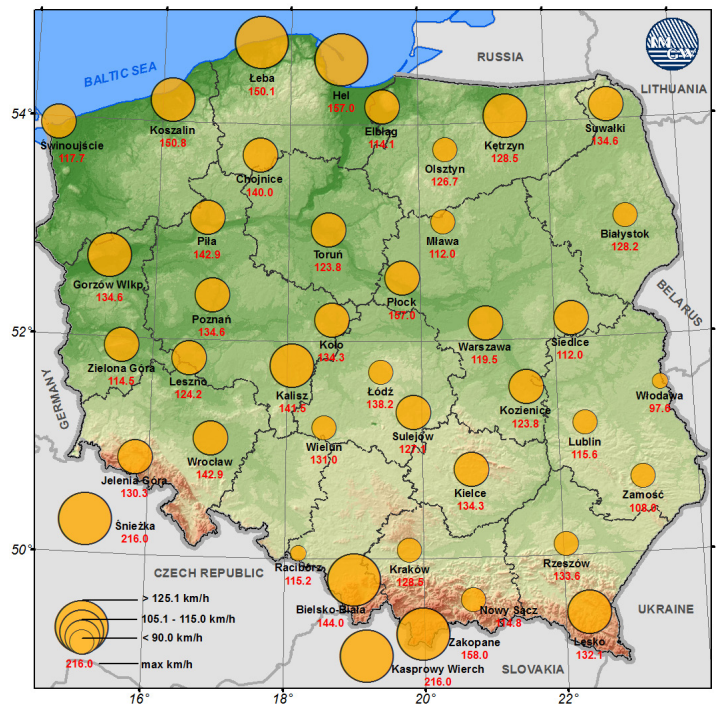

Fig. 5. Spatial distribution of maximum wind-gust speed $(\mathrm{km} / \mathrm{h})$ with return period of 10 years (January)

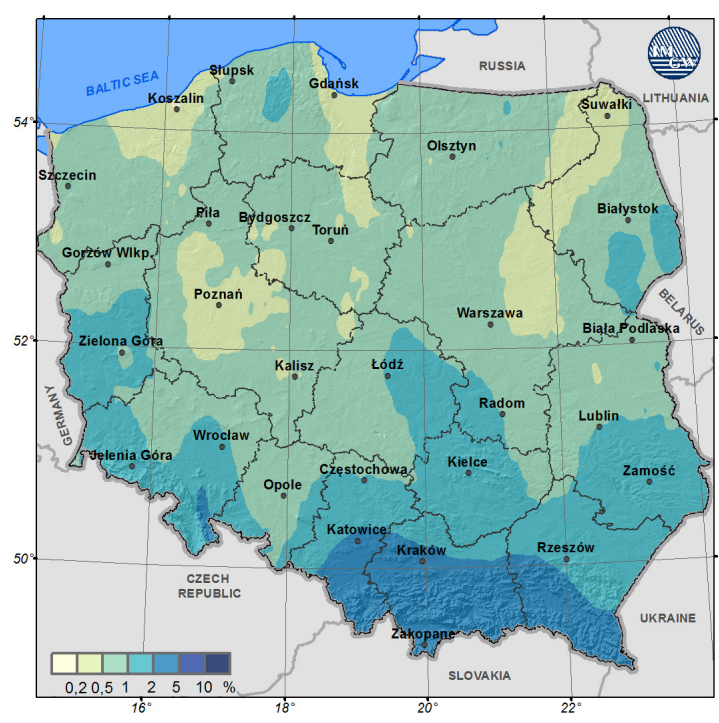

Fig. 6. Frequency (\%) of daily precipitation totals $>30 \mathrm{~mm}-$ May, 3rd decade

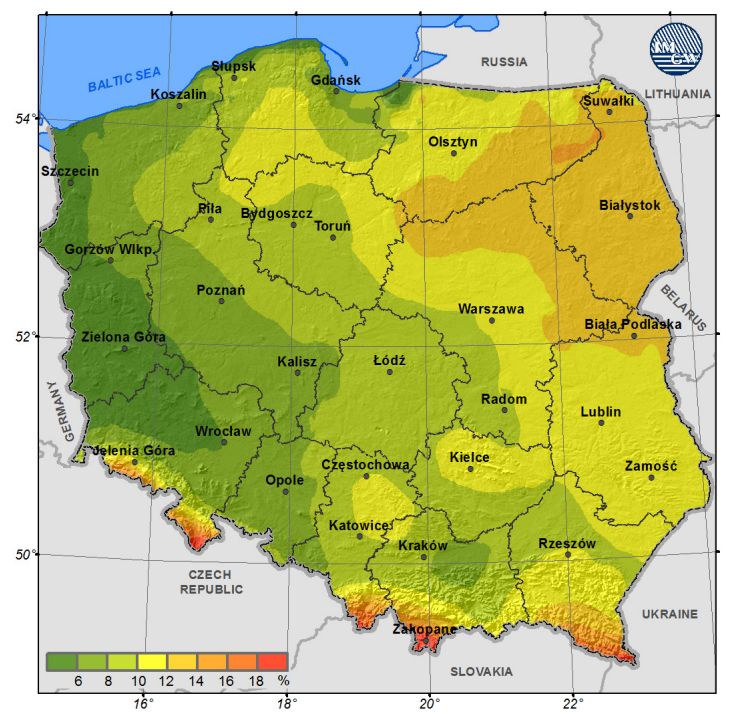

Fig. 7. Frequency (\%) of conditions favourable for glaze occurrence - glaze season (October-April) 
forecasts in Poland. The data from the ALADIN mesoscale atmospheric model, which, as suggested, predicts weather for a limited area, will be the core of the maps construction. Consequently, the maps will display potential threats estimated from values calculated by the model only. Though the resolution of the model is relatively high, the information within it should be analyzed with regard to a regional scale.

Warning maps will be created according to three different schemes that constitute the background of the climatological information. The maps produced up to arbitrary thresholds or probability approaches will present regions with very high, high, and moderate warning of the occurrence of the forecast phenomena (see scheme, Fig. 1), which means in practice that the phenomena (taken into account as one of the analyzed elements) are forecast and have the potential to achieve hazardous intensity.

At the same time, since the presence of weather phenomena such as hailstorms, fog, rime, glaze, and snow cover, is not directly predicted by the ALADIN model, it was decided that the historical information (about the occurrence and duration of a phenomenon) would be used to design (with forecast parameters) algorithms describing the conditions that favour a particular phenomenon. Therefore, the maps will present the regions with very high, high, and moderate, warning of the occurrence of atmospheric conditions favourable (see scheme, Fig. 2). In a practical sense, in some areas (those which are environmentally predisposed) the intensity of phenomena may be greater than predicted; in others, in spite of their previous affirmative forecast, they may not even occur.

\section{Discussions}

The object of weather hazard maps constructed in the ISOK system is to present the spatial differentiation of weather phenomena both in a historical and prognostic approach. Detailed climatological analyses, conducted in order to recognize the phenomena and the processes that lead to and sustain them, or the factors that affect their intensity, are one of the early stages necessary for the estimation of the risks which accompany the occurrence of given weather conditions. In addition to the evaluation of the absolute values, as well as the probability of occurrences of extreme phenomena in a given region, insightful case analyses were conducted, in which the causes (both synoptic and environmental) of their occurrence were recognized. The so-called conditions favouring the occurrence of a phenomenon were defined. It is possible, thanks to this approach, to issue credible weather forecasts which, in addition to the information provided by the mesometeorological model, also take the receptiveness of a region into consideration. Nevertheless, it should be noted that, apart from the current weather states, local factors, including environmental and socio-economic conditions, also have impact on possible occurrences of hazards. Only detailed analysis on a local scale, with, additionally, the incorporated complex influence of weather conditions, will allow us to determine the real threats and risks resulting from adverse weather conditions.

\section{Acknowldegments}

This material is based upon the work carried out by a team of forecasters from the Central Meteorological Forecast Office and researchers from the Institute of Meteorology and Water Management - National Research Institute. It was supported by the IT System for Country Protection against extreme hazards (ISOK) project POIG.07.01.00-00-025/09.

\section{Bibliography}

Brasseur O., 2001, Development and application of a physical approach to estimating wind gusts, Monthly Weather Review, 129 (1), 5-25

Brönnimann S., Luterbacher J., Ewen T., Diaz H.F., Stolarski R.S., Neu U. (Eds.), 2008, Climate variability and extremes during the past 100 years, Series: Advances in Global Change Research, 33, Springer

Casati B., Wilson L.J., Stephenson D.B., Nurmi P., Ghelli A., Pocernich M., Damrath U., Ebert E., Brown B.G., Mason S., 2008, Forecast verification: current status and future directions, Meteorological Applications. 15, 3-18

Dobesch H., Dumolard P., Dyras I. (Eds.), 2007, Spatial interpolation for climate data: the use of GIS in climatology and meteorology, ISTE, London, 284 pp.

Elguindi N., Bi X., Giorgi F., Nagarajan B., Pal J., Solmon F., Rauscher S., Zakey A., Giuliani G., 2011, Climatic Model RegCM User Manual - Version 4.1. Trieste, Italy

Golnaraghi M. (Eds.), 2012, Institutional Partnerships in MultiHazard Early Warning Systems, Springer Verlag, 243 pp.

Klein Tank A.M.G, Zwiers F.W., Zhang X., 2009, Guidelines on analysis of extremes in a changing climate in support of informed decisions for adaptation, Climate Data and Monitoring WCDMP-No. 72, WMO-TD No. 1500, 56 pp.

Soares P.M.M.,. Cardoso R.M, Miranda P.M.A., de Medeiros J., Belo-Pereira M., Espirito-Santo F., 2012, WRF high resolution dynamic downscaling of ERA-Interim for Portugal, Climate Dynamics, 39 (9-10), 2497-2522

Stanski H.R., Wilson L.J., Burrows W.R., 1989, Survey of common verification methods in meteorology, World Weather Watch Technical Report No.8, WMO/TD No. 358, WMO, Geneva, 114 pp.

Stephenson D.B., 2008, Definition, diagnosis and origin of extreme weather and climate events, [in:] Climate Extremes and Society, R. Murnane, H. Diaz (Eds.), Cambridge University Press, 11-23

Tiukało A., 2013, Analysis of instruments for assessment of planned investments in water management, MHWM, 1, 23-31

WMO, 2008, Capacity Assessment of National Meteorological and Hydrological Services in Support of Disaster Risk Reduction: analysis of the 2006 WMO Disaster Risk Reduction Country-level Survey, version on-line

WMO, 2012, WMO Disaster Risk Reduction Work Plan (20122015), version on-line 